\title{
Warning of warming
}

\section{How data and modelling led to predictions of climate change.}

\author{
The Discovery of Global Warming \\ by Spencer R. Weart \\ Harvard University Press: 2003. 240 pp. \\ $\$ 24.95, £ 16.95$, €23.10

\section{Stephen H. Schneider}

In the mid-1990s, as editor of the journal Climatic Change, I was sent a paper outlining the history of the international climate-change assessment process over the previous few decades. The Intergovernmental Panel on Climate Change (IPCC) had recently taken centre stage as the world's 'scientific consensus' on global warming. The article was written by a policy-studies graduate student who had rarely gone to any of the meetings he was reporting on, nor did he know most of the principals whose efforts he chronicled. I wondered how he could possibly get the events and flavour of this evo-

lution of climate efforts remotely right.

Nevertheless, I sent the paper to two senior climate scientists, both of whom had been present at the creation of this evolution of international cooperation in climate assessment. If the student, Shardul Agrawala, could get past these two tough reviewers, he would deserve to be published. I was amazed to receive two rave reviews. "How can someone who never was there do such a good and fair job that it reminded me of parts of this history I had forgotten?" one wrote. The paper was published with a few minor corrections and is now a standard for the history of this effort.

When I was asked by Nature to review Spencer Weart's history of the discovery of global warming, from the nineteenth to the twenty-first century, I was once again sceptical. According to his biography, Weart, a historian of science working at the American Institute of Physics, was not remotely a player in the climate debate. But, remembering my experience with Shardul's article, I began to read his compact little account.

It didn't take long for me to share the amazement of the reviewers of Shardul's paper. Weart's account brought back many forgotten memories of the great scientists I admired in the 1970s and had largely forgotten, including Murray Mitchell, Gilbert Plass and Fritz Moller. He also recounted the discoveries and issues raised by many others with whom I have been, or still am, friends

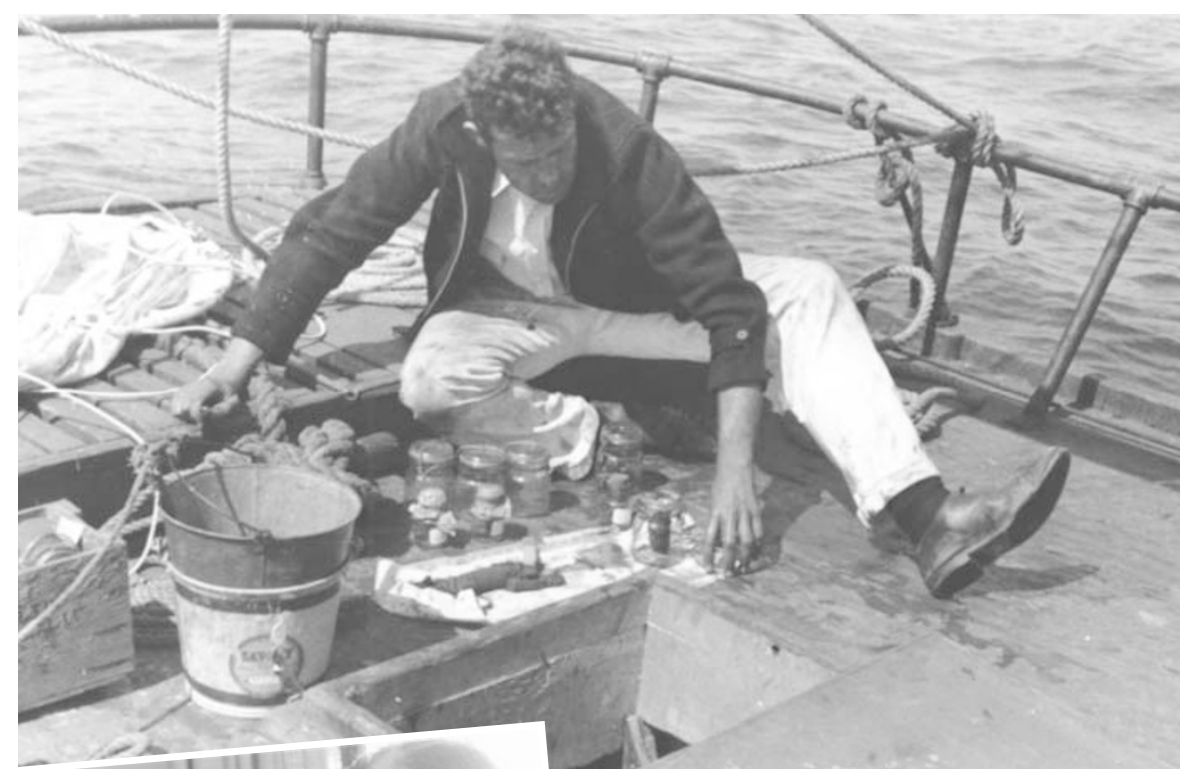

Getting warm: Roger Revelle (above) and Murray Mitchell were among the first scientists to detect signs of climate change.

the recent history and controversies surrounding climate change, has come across every possible website on climate imaginable, from exaggerated sites of 'deep ecology' non-governmental organizations to the shrill nonsense of 'enterprise institute' anti-warming sceptics and their political apologists in Congress and the business media. "It was such a pleasure to read such a fair and balanced account," she commented after checking out Weart's website.

In the final chapters of the book, Weart Revelle was my interdisciplinary mentor for 20 years, so I read the account of the work of Roger and his colleague Hans Suess in the 1950s with particular interest. "If just one of these men had been possessed by just a little less curiosity, or a little less dedication to laborious thinking and calculation, decades more might have passed before the possibility of global warming was noticed."

It is amazing that in such a short book, Weart has managed to stuff in most of the truly important events and characters in the evolution of the global-warming issue. To be sure, I could think of many issues that he left out - such as the need for transient calculations and the pioneers of signal-tonoise ratios in the 1970s who helped to bring about better interpretations of the model results - but Weart manages to cover many of these in an excellent website produced as a companion to the book (www.aip.org/ history/climate).

My research assistant, Janica Lane, who is helping me to edit my own website (http://stephenschneider.stanford.edu) on 
of professional 'contrarian sceptics' have been ideological, shrill and way out of step with mainstream science. This historian got it right, both in the past and where the issue is going. I only wish that more of today's journalists and politicians were so careful and insightful.

It is the unwritten duty of a book reviewer to complain about something. So let me do it with full narcissism. In citing my first atmospheric-science paper in 1971, which suggested that aerosol cooling could dominate greenhouse-gas warming, Weart says that the "equations and data were rudimentary, and critics swiftly pointed out crippling flaws". He is right about the crippling flaws, but what I am most proud of was pointing most of them out first myself in a 1975 paper and in my book written with Lynne Mesirow, The Genesis Strategy (Plenum, 1976). Weart does note a 1992 chapter in which I predicted that an unambiguous greenhouse climate signal would emerge from the climatic noise around the end of the century, but I had first made this point in The Genesis Strategy. Given the IPCC's comments about the "discernible" impact of humans on climate in 1995, I am pretty proud of my 1976 crystal-ball gazing.

But these few personal complaints are trifles. This is a terrific book. For example, despite the polemics today from those who point to uncertainties in climate science as an excuse for inaction, when the usual proposed actions such as carbon taxes would hurt their ideological or clients' interests, Weart recognizes that science operates that way: "Scientists rarely label a proposed answer to a scientific question as 'true' or 'false', but rather consider how likely it is to be true. Normally a new body of data will shift opinion only in part, making the idea seem a bit more or less likely."

This is a clear statement of the bayesian or subjective probabilistic framework that is becoming the standard for complex assessments of problems such as climate change. I only wish more of my own colleagues were as epistemologically sophisticated about uncertainties and subjective probabilities as this historian (see Nature 418, 476-478; 2002).

Perhaps the finest compliment I could give this book is to report that I intend to use it instead of my own book Coevolution of Climate and Life (Sierra Club Press, 1984) for my climate class. The Discovery of Global Warming is more up-to-date, better balanced historically, beautifully written and, not least important, short and to the point. I think the IPCC needs to enlist a few good historians like Weart for its next assessment. Stephen H. Schneider is in the Department of Biological Sciences and co-directs the Center for Environmental Science and Policy, Stanford

University, Stanford, California 94305-5020, USA.

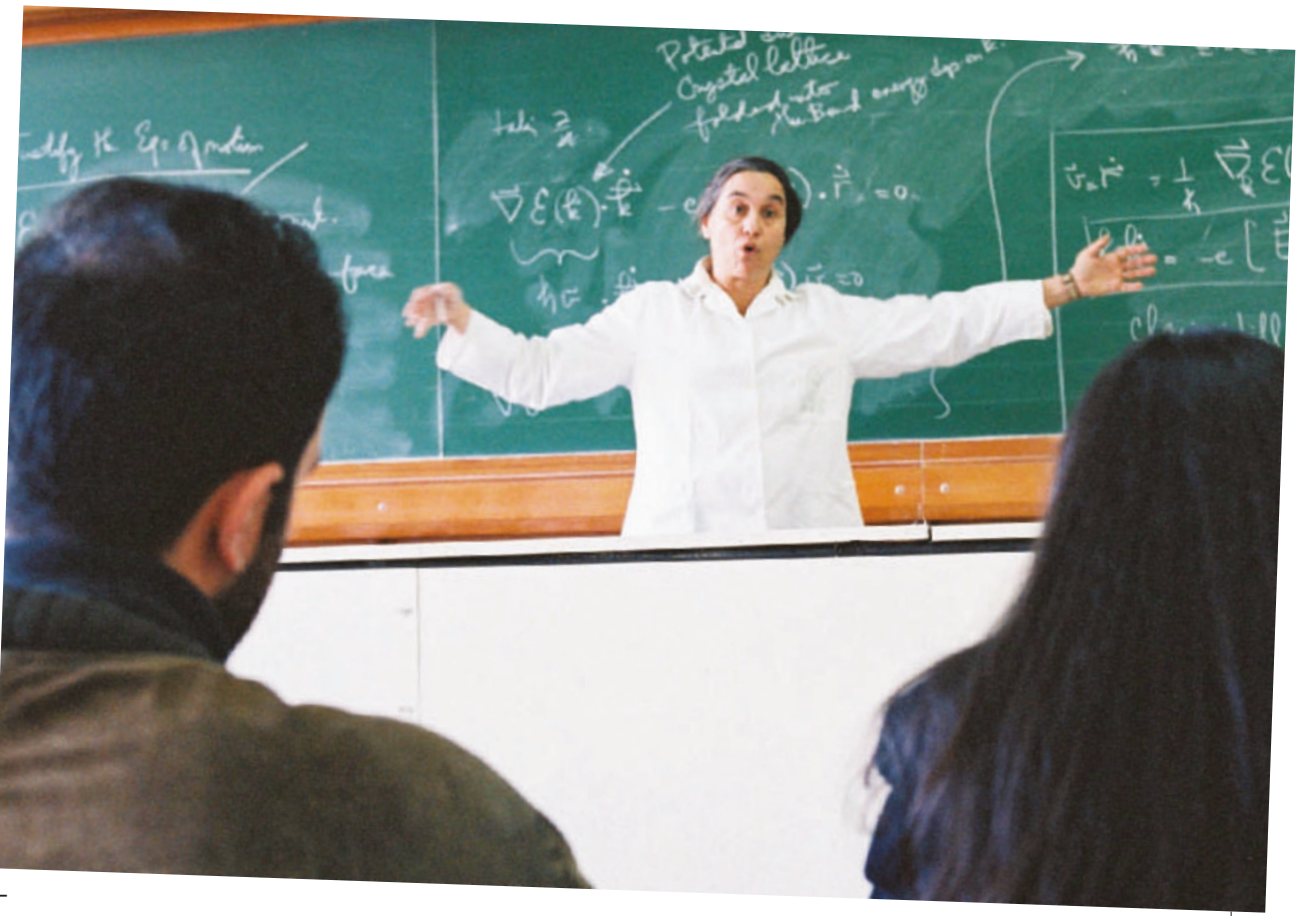

Role model: physicist Ayse Erzan won the 2003 L'Oréal-UNESCO For Women in Science award.

$\ldots \ldots \ldots \ldots$ And it is one-dimensional, regarding women's

The parenting gap

\section{Women in Science: Career}

Processes and Outcomes

by Y. Xie \& Kimberlee A. Shauman

Harvard University Press: 2003. 336 pp.

$\$ 59.95, £ 38.95$

\section{Abigail J. Stewart and Danielle LaVaque-Manty}

Do young women take fewer mathematics and science courses in high school than young men, leaving them less prepared and therefore less likely to major in science and engineering fields in college? Is a woman with a bachelor's degree in science and engineering more likely to have begun her college career as a science major, or on a non-science track? This book, ten years in the making, offers definitive and surprising answers to these and other long-standing questions about women in science.

Using an inventive approach to deal with the paucity of data, Yu Xie and Kimberlee Shauman examine the question of women's under-representation in science by combining a 'life-course perspective' with the statistical analysis of 17 nationally representative data sets.

The life-course perspective assumes that major transitions in people's lives are "agedependent, interrelated, and contingent on (but not determined by) earlier experiences and societal forces". By contrast, the more familiar conceptualization of career trajectories in science and engineering is a "science pipeline". This pipeline is unidirectional: participants enter the pipeline by taking maths and science courses at school, and leak from it at various points when they stop pursuing coursework or careers in science.
And it is one-dimensional, regarding women's
relationship to science in isolation from everything else.

The analysis of multiple data sets allows the authors to construct 'synthetic cohorts' of women, or 'hypothetical cohorts whose life history is constructed from real cohorts', whose career processes can be compared to those of synthetic cohorts of male counterparts. The composite portrait generated should reasonably represent the lifetime career trajectories of the population of women in science.

The care that the authors take with their empirical approach allows them to offer definitive answers to important questions. They find that although young men are twice as likely as women to enter college with the intention of majoring in science or engineering, this is not explained by gender differences in high-school maths achievement or coursework. The gender gap in mathematics achievement is small and has been declining, and girls not only take as many maths and science courses as boys, but also get significantly better grades in them.

More surprisingly, Xie and Shauman find that the majority of men who get baccalaureate degrees in science or engineering pursue those degrees throughout their college years, whereas most of the women who graduate in these fields enter science and engineering during college after starting on non-science tracks. This discovery complicates the unidirectional image of the leaky pipeline.

Several chapters in the book point to the role that having children plays in women's career trajectories. Married women with children are most likely to leave science and engineering after completing a degree. They are also less likely to be employed, promoted or geographically mobile than either their 